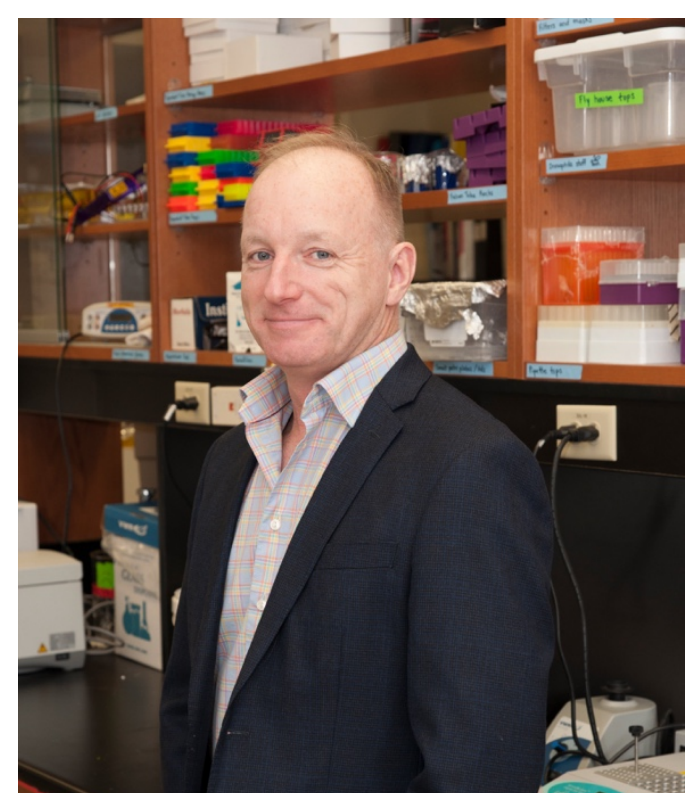

\section{Western Faculty Profile: Dr. Graham Thompson}

\author{
Dana Nguyen ${ }^{1}$ \\ ${ }^{1}$ Faculty of Science, Western University, London, Canada \\ No conflicts of interest declared
}

\section{Background}

Dr. Graham Thompson is an Associate Professor in the Department of Biology at the University of Western Ontario. He completed his Bachelor of Science and Master of Science in Zoology at the University of Guelph, before going on to complete his PhD in Genetics and Evolution at LaTrobe University. He then went on to complete postdoctoral fellowships at James Cook University, Simon Fraser University and the University of Sydney. He currently teaches undergraduate biology courses, including Animal Behaviour, Behavioural Genetics, and Behavioural Ecology, as well as a graduate seminar course in Behavioural Ecology. His research focuses on the biological basis of insect social behaviour. Dana Nguyen, a member of the Academic Affairs Committee for WURJHNS, had the pleasure of interviewing Dr. Thompson to learn more about his career path and his research.

\section{Tell us about yourself and your career path.}

My name is Graham Thompson and l've been a Biology professor here at Western for ten years. I grew up in Ottawa, and after high school attended the University of Guelph to complete my undergraduate degree and then my Master's degree in Zoology. I would say things started happening for me in my fourth year of undergrad at Guelph. Prior to that, I was just a completely normal student - unnoticeable until fourth year, when I took a course called "Animal Behaviour" (which is now, as luck would have it, the course that I teach). The professor in that course explained to me, in a way that I could understand, how the whole process of natural selection works. Up to that point, so much of my undergrad had been about massive amounts of pure memorization - which I'm sure is still true today. It wasn't until I took this Animal Behaviour course, which was synonymous with me learning about evolution at a conceptual level, that my whole undergraduate degree retroactively started to make sense to me. This is when that light bulb in my head of what I was interested in kind of clicked on for me.
Also in fourth year, I went on a field course in Jamaica. During that trip, I did a project on animal behaviour and genetics, which later became the basis for my graduate work the following year. I hadn't planned on going into graduate work - it just unfolded that way. I was quite proud of my fourth-year undergraduate thesis, and so I approached the professor that hosted the field course and said, "Don't you think this is cool? Wouldn't it be neat to redo it ten times better as a Master's project?". Even though it was outside of his normal research program, the professor agreed with me and took me on as a graduate student. This then led in to my PhD work, and then to my postdoctoral fellowship work in Australia. I'd been a postdoctoral fellow at the University of Sydney for about five years or so when I was offered a faculty position here at Western - and l've been here ever since.

\section{What is your main research focus currently?}

Our research focuses on the evolution of animal behaviour - in particular, social behaviour. We explore the evolution of societies; how societies evolve in the first place and why they evolve. We explore the different types and variations of societies that exist in the animal world. Furthermore, we study the social conflicts that can arise, and how these conflicts are mediated. We also study different situations, about why cooperation between individuals occur in some instances and conflict occurs in others. Our usual approach to resolving that is to test whether the interests of the individuals are aligned - in particular their respective reproductive interests. This a starting point to understand how conflict versus cooperation arises, and thus can be used to predict where it could arise in the future.

The broadest term we could associate with all of this is sociobiology - the biology of social living and social societies. Essentially anything to do with sociality. A lot of sociobiology has focused on humans, understandably, but we draw from the most general aspects of sociobiological theory. We make a point of being expert in that - and we don't typically apply it to human societies. We apply it to other types of animals, often insects. That brings us to work with familiar organisms like honeybees, and in 
our lab's case - termites. Other researchers in the field might also work on ants and wasps.

I would say our work is on evolutionary biology as well as sociobiology. Since we are dealing with evolution, we also tend to work on genes and study genetic effects. This brings us to work with a lot of molecular biology equipment, such as PCR, sequencing and all manner of bioinformatics. So even though our work is a little bit philosophical, we're also quite empirical. I think that's our strength - we find our success by being good at combining theory with empiricism. We're not dedicated theorists and we're not a massive throughput empirical lab either - but we deftly interdigitate the two. I like to say that we do small science but smart science.

\section{What sparked your interest in sociobiology?}

The Animal Behaviour course I took during my fourth year of undergrad definitely peaked my curiosity in the field. I just thought it was interesting how animal behaviour could be understood and explained, and used as a model to understand broader principles. Thinking about why different animals have different breeding systems, or the variations in the way that different species organize themselves to reproduce, or the conflicts that arise and the alliances that form between males and females or between two females, and then thinking about how those things break down - it's interesting in a David Attenborough kind of way. Simply that it happens is interesting, but the David Attenborough level is superficial. It doesn't explain why these things have evolved this way. If you introduce evolutionary biology into it though, in the Richard Dawkins sense, then you can really understand why this is happening. I just thought it was so cool to think that these are the reasons why these behaviours are happening. And with this, I was armed with a new understanding of the living world as I went on my field course in fourth year.

The field course I went on was called Tropical Biology; it was in Jamaica at a marine center. Everybody in the course went there to get a tan, be cool and scuba dive on the reef. I did that too of course, but at the end of the course we had a few days to do a project. Up to that point, we'd just been doing modules and preplanned exercises. The last few days though we were free to do our own projects. Everyone in the course did some project on the marine reef, and I was the only one that did a terrestrial project. I decided to do my project on social insects. I had no expertise on the subject at all - it just so happened as a coincidence that on the grounds of this marine center in Jamaica, there were all these conspicuous termite nests in the trees. I thought, "Wow, I wonder if I could sample some of these termites, genotype them and do a little Punnett square - could I infer the genotypes of its parents?" I was able to do that and that was my little fourth-year project. And then I thought about how powerful this was. I was able to sample just a couple dozen individuals from this colony of a million - and without sampling the reproductive parts at all, I could infer what the parents' genotypes MUST have been. If I do that for many colonies, then I could do a population genetic estimate of how inbred or outbred individuals in the population are. In a way it was clever, but it was also very basic. At the end of the course, I stood there with my undergrad report, walked with it into the office of my future Master's supervisor (who was Paul Hebert at the University of Guelph) and said 'Wouldn't it be cool to redo this project ten times better as a Master's project?", and on a whim, he said "Yeah, let's do it." and signed me up. My project wasn't his field exactly, so I was the odd man out in the lab. It was a challenge to be doing something different from everybody else in the lab, but at the same time it helped me to carve an identity for myself.

\section{What advice do you have for undergraduate students?}

Firstly, I think it's important to know that, in a way, you can create your own destiny. In my own case, my Master's project wasn't exactly aligned with my supervisor's research and his lab. But I took a shot at it anyway and he ended up taking me on. It's a good lesson, because it just shows you can create opportunities for yourself. You can follow your own interests, you don't have to sign up for a predetermined certified program through which you will graduate. Often when I talk to undergrads about what they're aspiring to be, the answer is invariably to sign up for some predetermined certification - obvious ones like becoming a doctor, dentist, teacher or vet etc. Those are all perfectly great professions but they're safe, because we've all heard of those things since we were 6 years old. These are things that people know and are familiar with, and when you say that you want to be that or do that, there's a certain comfort in it. But what if you just said - I'm interested in, say for example, science communication or policy. What's the word for that? I don't know, but just follow your interests and you'll end up in a job that you've never even heard of before. You would never have thought of that when you were 6 years old or even 19 years old - but you just followed your interests. And your interests can change all the time. There's a core element that probably remains the same, but it's not something that you have to pick when you're in first year. In fact, it's kind of detrimental. I think that some people think that it's a sign of strength to NEVER change your mind - but I think that's just a lack of imagination and a certain cowardice, because it means you're afraid to make lifechanging decisions. You've just latched on to this thing and out of fear of change, you're never going to respond to new opportunities - even though every semester and year you're being bombarded with new information that must surely be expanding your horizons. My point is just that it's okay to be flexible, and to react to new information and experiences.

Of course, it's good to have a goal for your career, but the goal can be a general one. Just be open and work towards fields that you're interested in. Undergrad is such a time of selfawareness - you discover that you have a) an interest in something, and b) a skill in something. Where these two things, your interest and your aptitude, overlap - that's where you want to be. That's where you want to be in the Venn diagram of life.

Choosing a career is not like ordering off a menu - often the mindset of choosing a job is that it's a pre-determined thing because it's something you want for yourself. It's a selfish thing like this is what I'm going to get. I'm going to get a job in, say for example, dentistry because it's a job for me. It's something that you are acquiring for yourself. But what if you flipped your attitude around and said "It's not about something that I can get - but it's what I can contribute to the world." That changes the whole dynamic of your approach. Ask yourself - how can I deploy what's inside of me to the outside world? How can I fill a void that needs filling? In other words, if there's a demand for something - how can I be the supply? If you define yourself as the supply that's needed to fill the demand, then whatever that job is called - that's your job. I think it's much more imaginative and more efficient to 
think of it as a supply and demand, where you are the supply. You can recognize the demand and then put yourself there.

A job should be something that is of value to the community, to society, and to the world. In principle, the reason why you get paid is that, presumably, what you're doing is worth something. It's worth the pay. Society is paying you money in proportion to the value of your contribution. If you think of it like that, you can ask yourself - how can I be of value to my community? And that's such an open space. That's a better way to look at it - how can I supply value to my community, as opposed to what can I selfishly get out of that job.

One other big piece of advice that comes to mind is to be mature. To be socially mature and to be professionally mature. I think a big deterrent to potential employers or supervisors is that students sometimes come across as a little bit selfish, needy, and immature. There are many students who will knock on every door with "I've never had a job before, I don't have any skills that I recognize in myself - but can you hire me?" It's important to be upstanding, and to have something to offer, as opposed to seeking out handouts. If you give the impression that your presence will create more work for your supervisor, they won't want you. They want to know how you're going to make their life easier, not harder. It's important to recognize your own skills and demonstrate your ability to carry them out - it shows that you can supply a demand, as opposed to seeking a handout. An average undergraduate student's mindset is what they can get, and it should be about what they can give. It surprises me sometimes how prevalent the giveme mindset is.

I also think that a lot of undergraduate students don't realize that a prof is more than just a person that marks your exam and gives lectures. Just being aware of that can make the biggest difference. For most undergrads, the only time they interact with the prof is when they are in a huff and saying "How come YOU took off half a mark here?" From the prof's eyes, it's very immature behaviour, because the prof is investing a ton of time and effort into developing the expertise to get into that position to teach you. And then probably has to go through all sorts of administrative processes to get assigned to a particular course. And then when they own the course, they have to write all the lectures - and for one lecture, it's probably 8 hours of prep just to get the right content, and to get it aligned with the whole course. Then they have to mesh it with the labs, train the TA's, write up the exams, deal with all the marking and accommodations and adjudications and SSD etc. It's a ton of stuff. And then the only interaction you get with the student is this red-faced foot pounding "WHY did you take half a mark off?" It's important to have a sense of maturity about all the work that's gone into developing and executing a course. And even though undergraduate mentality, understandably, is about chasing marks, it's also important to have interpersonal skills. If you're going to approach a prof about marks, do it in a way that is impartial. Try to seek a deeper understanding, as opposed to treating it as some judicial process where you're trying to be right and the other person has to be wrong. Basically, do not be offended. If there is an adjustment to be made, then it'll be made. I think some students ruin their first impression by being that snotty undergrad. There's tons of tangential benefits to just developing a nice, normal, mature, professional relationship with your colleagues, which include people of different ages and career stages, including profs. So, I would say my advice is just to be professional.

Imagine if you weren't just an undergrad sitting in a class, but that you've just been hired by a bank - you show up on time, you're well rested, you are well-presented and you deal with people in a professional and courteous way. It's business-friendly. As general advice, I would just consider your interactions on campus to be business-friendly. It's obvious that marks are important, but at the same time, when a future employer is looking at your CV, sometimes the marks are not that important or only important in a certain context. If someone is looking at your precise marks, it'll only be looked at as one of many different criteria. So, for example, if you have a 75 (as opposed to a 95) but you have two summers of work experience - it says volumes about you. It shows that you strive to be a professional and that you're on a forward trajectory, that you're mature and that you're experienced. Here, marks alone don't win the day. Marks are important, but they're not all-important. Be professional and well-rounded, and you'll get where you need to be.

\section{To Learn more on Dr. Thompson's lab and research, please visit his website at:}

http://www.uwo.ca/biology/faculty/thompson/ 